$\xi=-1$

\title{
Ontology Development for Medical and Health Science Domain in the Quran
}

\author{
Muhammad Afifi Mohamad Safee ${ }^{1}$, Madihah Mohd Saudi ${ }^{1,2 *}$, Kamarudin Saadan ${ }^{1}$ \\ ${ }^{1}$ Faculty of Science and Technology, \\ ${ }^{2}$ Cybersecurity and Systems Research Unit, Islamic Science Institute (ISI), \\ Universiti Sains Islam Malaysia (USIM), Negeri Sembilan, Malaysia \\ *Corresponding author E-mail: madihah@usim.edu.my
}

\begin{abstract}
Ontology is known as a knowledge representation and acts as a sharing platform for common ideas within a similar domain. It has a tree structure to ease the information presentation to users. Nowadays, it is very important to have a consistent and systematic way of presenting and retrieving different sources of knowledge such as the Quran and Hadith. Since there is so much useful information that can be retrieved from the Quran, especially for the Medical and Health Science domain, this paper presents the development of ontology for the Medical and Health Science domain in the Quran by adopting the Ontology 101 approach. These include the scope and domain determination, competency question formulation, ontology construction, and ontology evaluation. The proposed ontology in this paper has successfully retrieved the correct answers for Medical and Health Science using related queries via SPARQL-query and has been evaluated by the domain experts. Furthermore, the ontology structure accuracy has also been verified using reasoner, where it detected inconstancy during ontology development. For future work, this research paper can be used as a reference and basis to answer user queries, data integration with other applications or this ontology can be further expanded.
\end{abstract}

Keywords: Domain Expert; Medical and Health Science Ontology; Ontology Engineering; Quran Ontology.

\section{Introduction}

The Quran has served Muslims to provide a complete code of life to live on the Earth. As Arabic language is the original language for the text and only the natives can only understand, this shows a need for Muslims across the world to find the meanings of these words in their own language for them to understand the content of the Quran. To a certain extent, appropriate experts are needed to understand and retrieve the Quran knowledge. For non-experts, they are having a hard time to understand and retrieve knowledge from the Quran [1]. However, with the aid and support of computer technology, these issues can be solved, especially through the web environment.

Currently, one of the existing approaches to present the Quranic knowledge is by using a tree-structure hierarchy. Yet, this approach has limited capability to identify the actual meaning of the concept in the Quran [2]. Apart from that, inconsistencies in the structure of the Quranic domain also make it difficult to use and share data at the syntactic and semantic levels [3]. As for the semantic level, ontology offers a good solution for using and sharing data. It is a modelling tool that provides a formal description of concepts and their relations, as a foundation for semantic integration and interoperability. Nevertheless, existing works on Quran ontologies are limited in scope, capability, and knowledge hence, there is a need to fill this gap [4].

Therefore, this paper presents the development of ontology for the Medical and Health Science domain in the Quran. For this ontology development, the concepts are manually extracted by experts from the Faculty of Quranic and Sunnah Studies (FPQS) and Faculty of Medicine and Health Sciences (FPSK), Universiti Sains
Islam Malaysia (USIM). The concepts are extracted from different translation sources and structured using the ontology into a set of equivalent classes, properties, and relationships. Then, this ontology is evaluated using the SPARQL-query and domain experts. This ontology will be used as a basis for the Quranic index search engine.

This paper is organized as follows: Section 2 presents related works, Section 3 presents the ontology methodology processes, Section 4 presents the findings and evaluation of the ontology modeling, and Section 5 concludes and discusses the future work.

\section{Related work}

Currently, many existing works use ontology as knowledge representation in a wider context, especially for the Quran. Much effort has been done by different researchers and system developers to ensure that Quran knowledge can be disseminated and accessed easily worldwide [5]. For example, in [6] presented the direction of knowledge exploration in the Quran which included the scope, methodology choices, tools, and evaluation methods. Furthermore, they also discussed the challenges in the lingual aspect of Quran's natural language processing by different researchers. Meanwhile, in [7] have modelled the ontology and summarised the contextual information support based on expert knowledge for the last Juz of the Quran (Juz Amma). These have been evaluated based on competency questions.

Furthermore, there are few works on ontology for different scopes in the Quran such as by [2, 8-11]. As for [8], they have modelled nature related concepts of the Quran using OWL (Web Ontology Language) / RDF (Resource Description Framework). Meanwhile, 
in [9] developed Dates ontology on the prophetic food domain by applying OAsys approaches. As for [10], they built a domainspecific ontology (Tibb Al-Nabawi ontology) for the Prophet's medicine representation by applying the Ontology 101 approach based on Hadith. In [11] have developed Quran ontology systematically using knowledge theme-based classification based on faith and manner. Meanwhile, a group of researchers developed a domain ontology based on living creatures including animal and birds in the Quran [2]. They also proposed that the concepts of semantic web can be used as an implementation for semantic search in the Quran. Based on the above existing works, it can be summarised that Quran ontologies have different scopes and none have covered all scopes in the Quran [12]. Therefore, extensive research is required to create more domain ontologies in the Quran [2].

\section{Methodology}

Ontology modelling is a complex task. Ontology development is not new as several methodologies and methods has already been proposed. The comparative study was carried out by [13-14] METHONTOLOGY is said as a prominent approach used by researchers [15]. Nevertheless, the work carried in [16-17] concluded that there are no methodologies that fit to develop any ontology with various viable alternatives. The basis of developing an ontology depends on the specific requirement for application domain itself. The Ontology Development 101 method proposed by [16] has been chosen as the basis and guidance for this research paper's ontology modelling. This methodology consists of five phases: specification, integration, conceptualizations, implementation and evaluation, as shown in Figure 1.

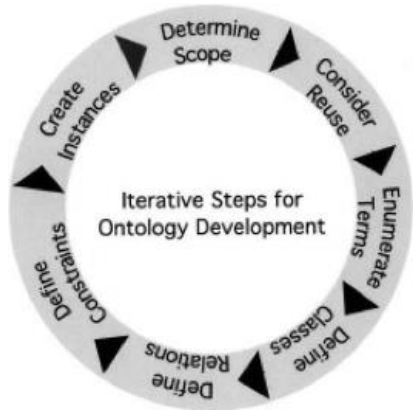

Fig. 1: Ontology 101 development steps

Ontology development, which is an iterative process, enables it to be developed from a smaller scale. Testing, evaluation and further expert review are needed for any initial prototype ontology [16]. The implementation step of this method for this research paper is as shown in Figure 1. Every implementation phase is explained as follows:

\subsection{Determine the domain and scope of the ontology}

This phase describes the domain, purpose and scope of the ontology. For this research, Medical and Health Science concept in the Quran has been chosen as the domain and scope, which also used as the basis for Quranic Search Index and as a reference for the Quran and Medical experts to exchange knowledge from various Quran verses related to the medical and health science field. The scope of the research is determined as displayed in Table 1.

Table 1: Ontology Domain and Scope

\begin{tabular}{|l|l|}
\hline Ontology 101 [16] & Research Paper Domain and Scope \\
\hline $\begin{array}{l}\text { What is the domain that the } \\
\text { ontology will cover? }\end{array}$ & $\begin{array}{l}\text { It covers medical and health science } \\
\text { terminologies that are related to the } \\
\text { Quran }\end{array}$ \\
\hline For what we are going to use & It provides the knowledge base of Quran \\
\hline
\end{tabular}

\begin{tabular}{|l|l|}
\hline the ontology? & $\begin{array}{l}\text { verses and explanations that are related } \\
\text { to the medical and health science field. }\end{array}$ \\
\hline $\begin{array}{l}\text { For what type of questions in } \\
\text { the ontology should provide } \\
\text { answers? }\end{array}$ & $\begin{array}{l}\text { It answers questions related to the verses } \\
\text { and translation that are associated with } \\
\text { the medical and health science scope. }\end{array}$ \\
\hline
\end{tabular}

\subsection{Consider reusing existing ontology}

There are two types of approach to build ontology, which is by creating from scratch or reusing existing ontology. Reusing the existing ontology is the best approach as it helps to shorten the development task [16]. Many ontologies for the Quranic domain have been developed and reviewed by $[4,18]$. Since most of the Quran ontologies are domain-specific ontology, most of the concepts are different, except for the general concept (upper domain) which is Surah, Juz and Verses. There is only one Quran ontology that can be reached and downloaded that was developed by [19]. However, this ontology has inconsistency errors when tried to be matched with other ontologies as discussed in [4]. In [20] suggested to develop ontology from scratch if the price of developing a new ontology is lower than correcting existing ontology. Thus, the Quranic Medical and Health Science ontology is developed from scratch.

\subsection{Enumerate important terms in the ontology}

During the ontology development, the terms are gained from existing Quran ontology, Malaysian Research Development Classification System 5th Edition, and FPQS Quranic domain experts. From the knowledge acquired, the enumeration of terms was performed. For example, the Medical and Health Science class is classified into 27 other subclass domains such as anatomy, audiology, and immunology. Every subclass has another subclass and sibling class.

\subsection{Define the class and class hierarchy}

For this research paper, the classes are built by using Web Ontology Language (OWL) and Protégé software. OWL is chosen as it is capable to verify the ontology structure consistency and also provides automatic classification. Meanwhile, the ontology development combines the top-down and bottom-up approaches, where it generalizes and specializes ontology classes appropriately. The different classes created in the model are as shown in Table 2.

\begin{tabular}{|c|c|c|}
\hline $\begin{array}{l}\text { Class } \\
\text { Name }\end{array}$ & Description & Usage \\
\hline Quran & $\begin{array}{l}\text { Main concept of Quran } \\
\text { that has subclasses cate- } \\
\text { gories which are Ayat, } \\
\text { Juz and Surah }\end{array}$ & $\begin{array}{l}\text { To locate class Ayat, Juz and } \\
\text { Surah under Quran category } \\
\text { since Ayat, Juz and Surah are } \\
\text { part of Quran }\end{array}$ \\
\hline $\begin{array}{c}\text { Ayat } \\
\text { (Verse) }\end{array}$ & $\begin{array}{l}\text { Subclass of Quran which } \\
\text { includes all ayat of } \\
\text { Quran, defined as in- } \\
\text { stances }\end{array}$ & $\begin{array}{l}\text { To store all of Quran verses as } \\
\text { an instance. The Ayat(verse) is } \\
\text { used to search across Surah. }\end{array}$ \\
\hline Juz & $\begin{array}{l}\text { Subclass of Quran which } \\
\text { includes all Juz in the } \\
\text { Quran as instance }\end{array}$ & To store all Juz as an instance \\
\hline Surah & $\begin{array}{l}\text { Subclass of Quran which } \\
\text { includes all Surah in the } \\
\text { Quran as instances }\end{array}$ & To store all Surah as an instance \\
\hline $\begin{array}{l}\text { Medical } \\
\text { and } \\
\text { Health } \\
\text { Sciences }\end{array}$ & $\begin{array}{l}\text { Main concept of Medical } \\
\text { and Health Sciences } \\
\text { which include subclasses } \\
\text { and their instances }\end{array}$ & $\begin{array}{l}\text { To store Medical and Health } \\
\text { Sciences field of research based } \\
\text { on Malaysian Research Devel- } \\
\text { opment Classification System as } \\
\text { an instance. The field (the in- } \\
\text { stance) is use for searching } \\
\text { purpose, search from field and } \\
\text { subfield }\end{array}$ \\
\hline
\end{tabular}


Table 2 shows the ontology classes descriptions and their usage. As shown in Figure 2, the most general class is defined into 'Medical and Health Science' and 'Quran'. These classes are assigned under main class 'owl:Thing'. The first class which is 'Medical and Health Science' classifies the medical group domain based on 27 subclasses such as anatomy, audiology, and physiology. Every subclass (except for the 'Other Medical and Health Sciences' subclass) consists of several other groups such as 'allergy' and 'immunogenetics' which are subclasses of immunology. Thus, these sibling classes automatically become the superclass for 'Medical and Health Science'. Taxonomy can be seen from this subclasssuperclass relationship. Table 3 displays the taxonomy example for the therapeutic class. The highlighted class and subclass go into as a superclass for the more specific field assigned under it.

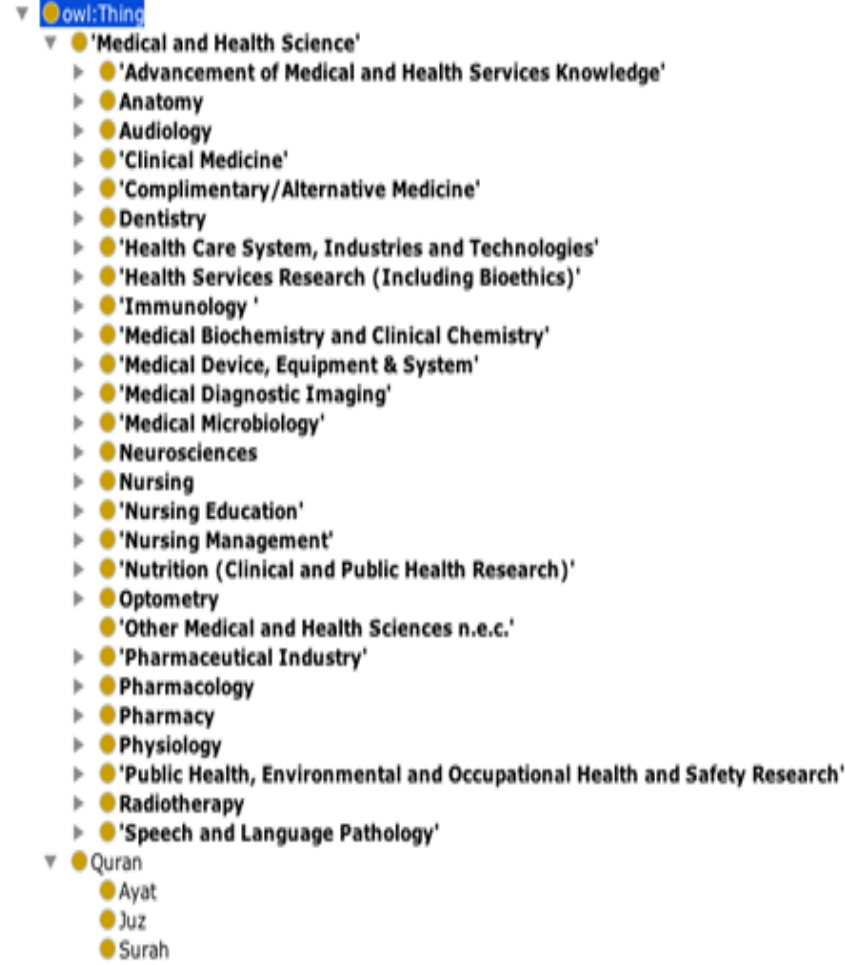

Fig. 2: Medical and Health Science class concept.

Table 3: Taxonomy of Therapeutic Class

\begin{tabular}{|c|l|}
\hline Superclass & \multicolumn{1}{|c|}{ Subclass } \\
\hline Thing & Medical and Health Science, Quran \\
\hline $\begin{array}{c}\text { Medical and Health } \\
\text { Science }\end{array}$ & $\begin{array}{l}\text { Audiology, Pharmacology, Neurosciences, Optom- } \\
\text { etry etc. }\end{array}$ \\
\hline Pharmacology & $\begin{array}{l}\text { Therapeutics, Radiopharmacology, Molecular } \\
\text { Pharmacology, Medical Pharmacology, etc. }\end{array}$ \\
\hline
\end{tabular}

\subsection{Define the properties of class}

OWL properties can be categorized into data properties and object properties. Data properties define relationships of individuals with literals that also called as attributes (see Figure 3). This literals value can consist as float, double, string, integer and Boolean. While, object properties define the relationship between pairs of individuals. The properties and the description are defined in Table 4. Meanwhile, the triple will be enriched after it has been calculated by reasoning tools.

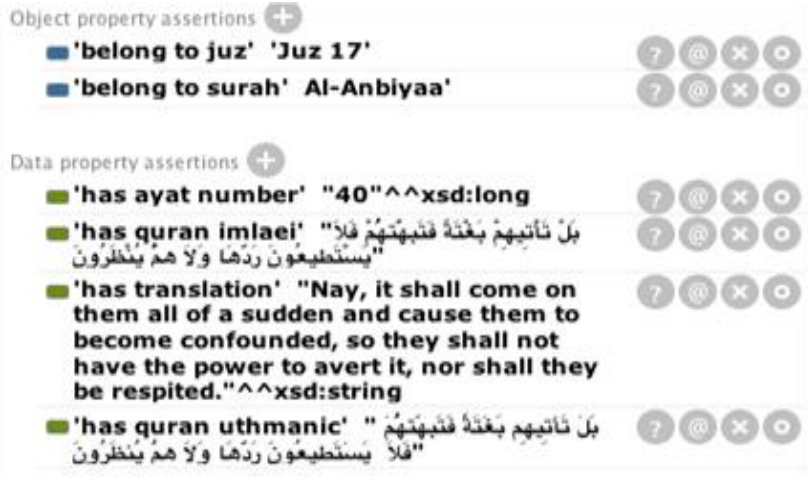

Fig. 3: Implementation of Data Property in Protégé.

\begin{tabular}{|c|c|c|}
\hline Name & $\begin{array}{l}\text { Data } \\
\text { Type }\end{array}$ & Description \\
\hline hasAyatUthmani & String & $\begin{array}{l}\text { Store the Uthmanie Arabic Quran verse } \\
\text { Usage: For searching purpose when user } \\
\text { searches using Arabic text }\end{array}$ \\
\hline hasAyatNumber & Integer & $\begin{array}{l}\text { The verse (ayat) number. E.g.: Al- } \\
\text { Baqarah Ayat } 5 \text { has verse number } 5 . \\
\text { Usage: The number is used for sorting. }\end{array}$ \\
\hline hasJustification & String & $\begin{array}{l}\text { Use to indicate the justification of the } \\
\text { Ayat } \\
\text { Usage: To be displayed on screen. It } \\
\text { explains the verse or translation. }\end{array}$ \\
\hline hasKeyword & String & $\begin{array}{l}\text { Use to indicate the keyword of the indi- } \\
\text { vidual (if any) } \\
\text { Usage: For searching purpose. }\end{array}$ \\
\hline hasSurahNumber & Integer & $\begin{array}{l}\text { Use to indicate the number of the Surah } \\
\text { in the Quran } \\
\text { Usage: For search result sorting }\end{array}$ \\
\hline hasTranslation & String & $\begin{array}{l}\text { Use to indicate the translation of the Ayat } \\
\text { Usage: For keyword searching from the } \\
\text { translation text }\end{array}$ \\
\hline hasDescription & String & $\begin{array}{l}\text { Use to indicate the description of the } \\
\text { instance (if any) } \\
\text { Usage: For displaying information pur- } \\
\text { pose }\end{array}$ \\
\hline
\end{tabular}

\subsection{Creating instances}

The instances in this ontology are developed by extracting the dataset by domain experts. Every content of the dataset such as related medical and health science domain field, keywords and justification were extracted by domain experts. For each extraction, an automated program is developed to parse, validate, and transform the source data to RDF triples. For this research paper, 693 verses and keywords from Juz 1 and 2 are imported as instances. These instances imported accordingly into their class concept category as shown in Figure 4 and Table 5.

\begin{tabular}{|c|c|c|c|c|}
\hline Codes & Surah & Verses & Keywords & Justification \\
\hline $\begin{array}{c}\text { F1100100 } \\
\text { IMMUNOLOGY }\end{array}$ & $\begin{array}{c}\text { Surah Al } \\
\text { Baqarah 2:184 }\end{array}$ & 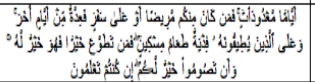 & 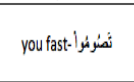 & "HIGHLY RELATED" \\
\hline $\begin{array}{c}\text { F1100100 } \\
\text { IMMUNOLOGY }\end{array}$ & $\begin{array}{c}\text { Surah Al } \\
\text { Baqarah 2:196 }\end{array}$ & 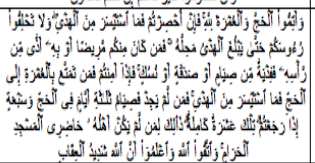 & مبنجإ. fast & "HIGHLY RELATED" \\
\hline $\begin{array}{c}\text { F1100201 Anti- } \\
\text { Oxidants }\end{array}$ & Surah Al Nahl 16:11 & 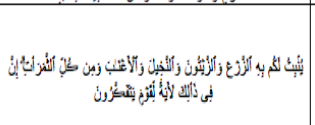 & 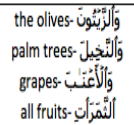 & "Highly related" \\
\hline
\end{tabular}

Fig. 4: Example of Medical and Health Science in the Quran dataset. 
Table 5: Summarization of Medical and Health and Science Domain

\begin{tabular}{|l|c|}
\hline \multicolumn{1}{|c|}{ Concept } & $\begin{array}{c}\text { Number } \\
\text { of Sub- } \\
\text { class } \\
\text { Concept }\end{array}$ \\
\hline Anatomy & 5 \\
Audiology & 19 \\
Clinical Medicine & 43 \\
Complimentary/Alternative Medicine & 12 \\
Dentistry & 21 \\
Health Care System, Industries and Technologies & 23 \\
Health Services Research (Including Bioethics) & 14 \\
Medical Device, Equipment \& System & 15 \\
Medical Diagnostic Imaging & 11 \\
Medical Microbiology & 5 \\
Neurosciences & 19 \\
Nursing & 36 \\
Nursing Education & 8 \\
Nursing Management & 14 \\
Nutrition (Clinical and Public Health Research) & 14 \\
Optometry & 11 \\
Pharmaceutical Industry & 18 \\
Pharmacology & 8 \\
Pharmacy & 14 \\
Public Health, Environmental and Occupational Health and & 21 \\
Safety Research & 10 \\
Radiotherapy & 18 \\
Speech and Language Pathology & 11 \\
\hline
\end{tabular}

\section{Results and discussion}

Ontology is evaluated to ensure the concepts have been correctly modelled based on their specific relationships to other concepts. Ontology 101 recommends three ways on the evaluation of performance which is by validating it using expert, using it in an application, or both.

This ontology has been validated by $12 \mathrm{Al}$ Quran and Hadith experts. The experts are led by Prof Madya Dr Adnan bin Mohamed Yusoff, dean at Fakulti Pengajian Quran Sunnah, Universiti Sains Islam Malaysia. A meeting has been conducted with an expert team to evaluate the correctness of the representation and the relation of ontology as shown in Figure 5. Additionally, competency questions created previously have been used to conduct the evaluation. The competency questions are intuitively converted into natural language. Hence, it must be translated into their equivalent representation in formal, machine-level query language. In Protégé, the formal query languages are the SPARQL and Description Logic (DL). However, Protégé cannot load a big file of RDF triples, therefore the ontology must be stored in a triple database. In [21] suggested Jena TDB because of its good performance and it supports ontology from a different format. The following subsection provides examples for three competency questions and their equivalent SPARQL queries.

The evaluation by executing SPARQL-query satisfied the results for the functionality of Quranic Medical and Health Science ontology. This indicates that the developed ontology fulfills the requirement and the usability. The ontology structure has also been evaluated by domain experts during the development process.

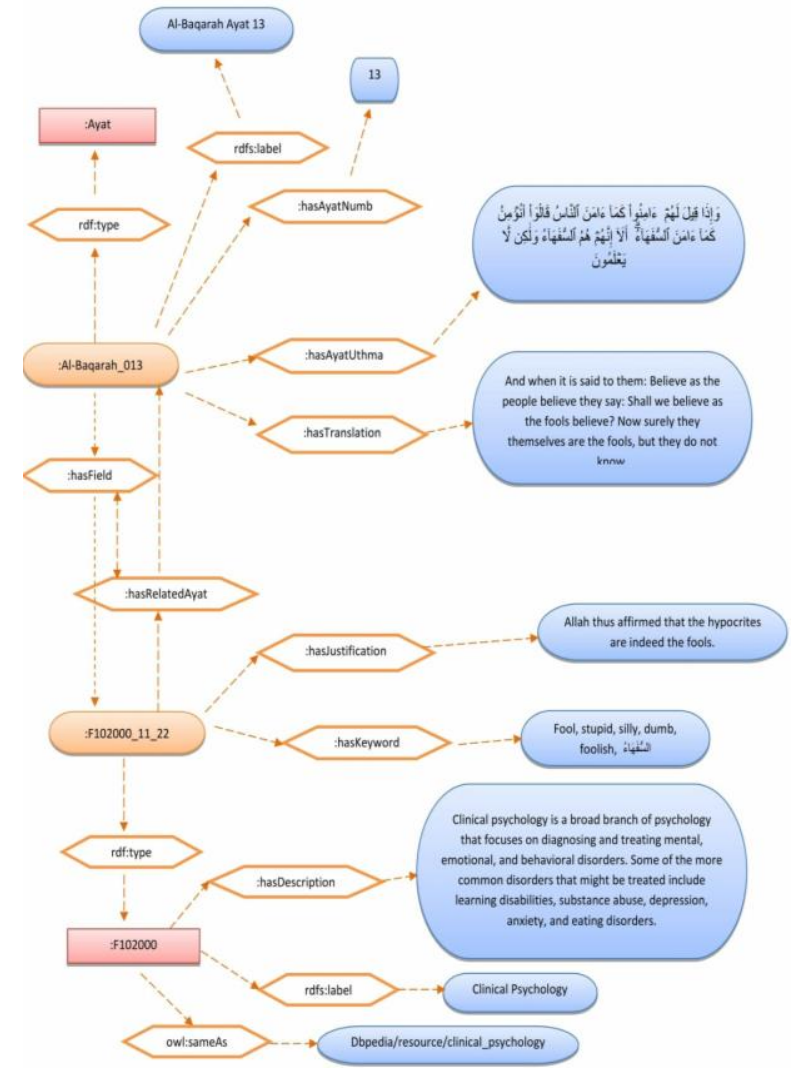

Fig. 5: Proposed ontology structure and relation.

Query \#1: What field is related to Al-Baqarah ayat 10 ?

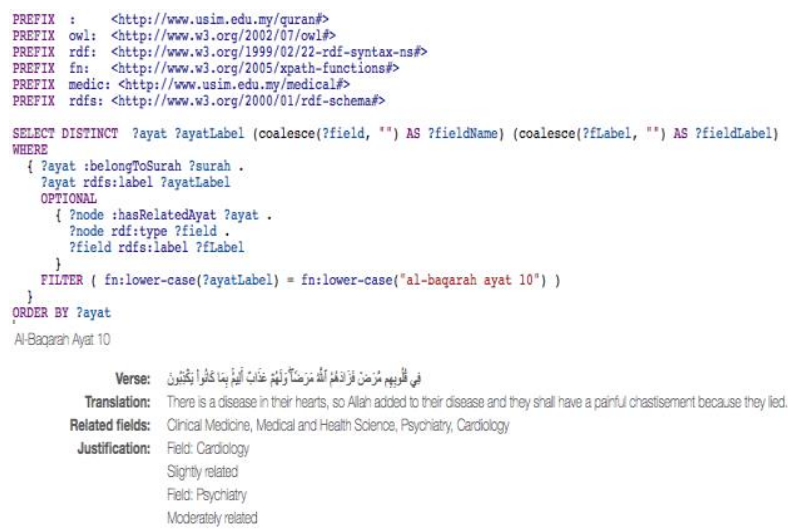

Query \#2: List all Surah/Verse related with Audiology?

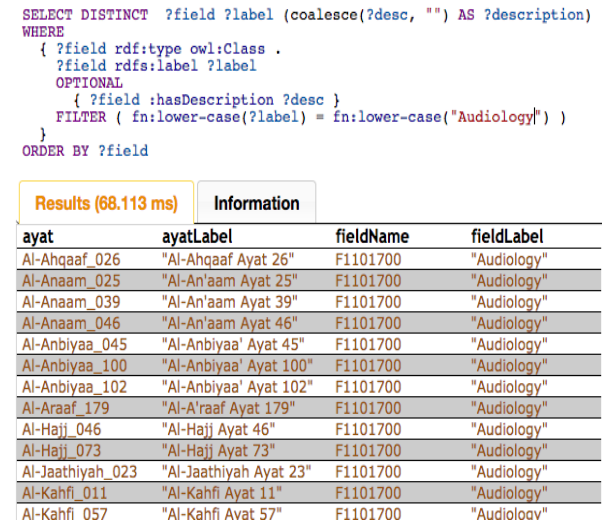


Query \#3: What field is related to the following translation: "but whoever among you is sick or on a journey, then (he shall fast) a (like) number of other days"

\begin{tabular}{|c|c|c|c|c|}
\hline \multicolumn{5}{|c|}{ 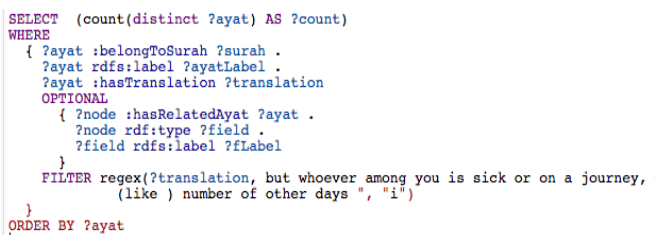 } \\
\hline \multicolumn{2}{|c|}{ Results (953.851 ms) } & \multicolumn{2}{|c|}{ Information } & \multirow[b]{2}{*}{ fieldLabel } \\
\hline ayat & \multicolumn{2}{|c|}{ ayatLabel } & fieldName & \\
\hline Al-Baqarah_184 & \multicolumn{2}{|c|}{$\begin{array}{l}\text { "Al-Baqarah Ayat } \\
184 "\end{array}$} & F1100810 & $\begin{array}{l}\text { "Preventive } \\
\text { Medicine" }\end{array}$ \\
\hline Al-Baqarah_184 & \multicolumn{2}{|c|}{$\begin{array}{l}\text { "Al-Baqarah Ayat } \\
184 "\end{array}$} & F1100100 & "Immunology " \\
\hline
\end{tabular}

To ensure the correctness of the structure of the ontology, the Fact++ reasoner [22] was used to detect some of the most common pitfalls that appear while developing ontologies. Fact++ is one of the reasoners that compatible with protégé. It has inference engines specializing in DL technology. It supports the inference services during the ontology development stages. Some of the services supported by these reasoners are identifying inconsistency and classifying taxonomy in the ontologies.

To test for an unsatisfiable status, the member "Cytology" of the concept "Anatomy" was inserted as an equivalent concept to "Dentistry". By default, the concept "Dentistry" is inserted as disjoint concept to "Anatomy" and all members of both concepts cannot be inserted as equivalent concepts. Therefore, unsatisfiable classified classes generate an error message that shows error in the taxonomy and inconsistent reasoning as shown in Figure 6. This was because of the erroneous equivalence that was made between "Cytology" and "Dentistry", where it should be an equivalence of "Anatomy" instead.

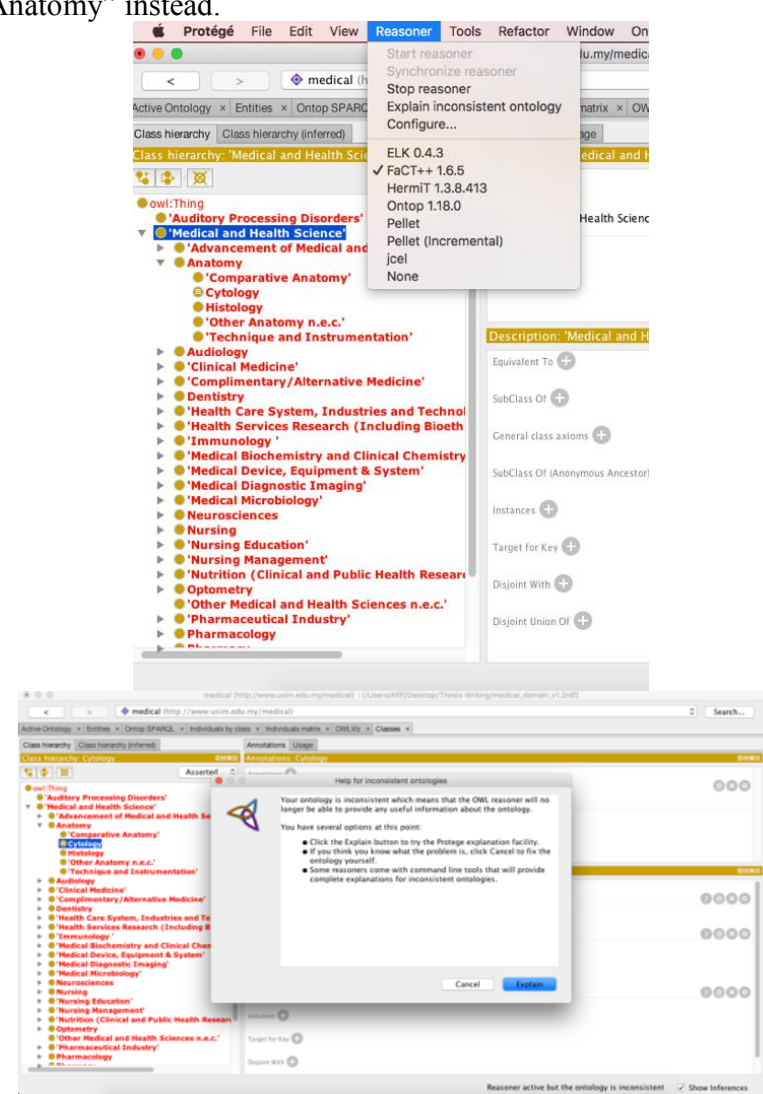

Fig. 6: Ontology validation using reasoner.

\section{Conclusion}

This paper presents the development of ontology for the Medical and Health Science domain in the Quran, where it employs the Ontology 101 approach. The proposed ontology has been evaluated and has successfully retrieved correct answers for Medical and Health Science related queries. The contributions of this research paper rely on the Quran verse data that have been categorized accordingly to their medical classes. For future work, this research paper can be used as a reference and basis to answer user queries related to the Medical and Health Science domain in the Quran, to integrate data with other applications or to expand this ontology.

\section{Acknowledgement}

This work was supported by the Universiti Sains Islam Malaysia (USIM) [Grant No: PPP/USG-0216/FST/30/15116].

\section{References}

[1] Nguyen, N. T., \& Rusin, M. (2006). A consensus-based approach for ontology integration. Proceedings of the EEE/WIC/ACM International Conference on Web Intelligence and Intelligent Agent Technology Workshops, pp. 514-517.

[2] Khan, H. U., Saqlain, S. M., Shoaib, M., \& Sher, M. (2013). Ontology based semantic search in Holy Quran. International Journal of Future Computer and Communication, 2(6), 570-575.

[3] Ismail, R., Abu Bakar, Z., \& Abd Rahman, N. (2015). Extracting knowledge from English translated Quran using NLP pattern. Jurnal Teknologi, 77(19), 67-73.

[4] Mohamad Safee, M. A. M, Mohd Saudi, M., Pitchay, S. A., \& Ridzuan, F. (2016). A systematic review analysis for Quran verses retrieval. Journal of Engineering and Applied Sciences, 100(3), 629634.

[5] Abbas, N. H. (2009). Quran 'search for a concept' tool and website. Master thesis, University of Leeds.

[6] Farooqui, N. K., \& Noordin, M. F. (2015). Knowledge exploration: Selected works on Quran ontology development. J. Theor. Appl. Inf Technol., 72(3), 385-393.

[7] Periamalai, N. S. H. A. R., Mustapha, A., \& Alqurneh, A. (2016) An ontology for Juz'Amma based on expert knowledge. Proceedings of the IEEE 7th International Conference on Computer Science and Information Technology, pp. 1-5.

[8] Sadi, A. S., Anam, T., Abdirazak, M., Adnan, A. H., Khan, S. Z., Rahman, M. M., \& Samara, G. (2016). Applying Ontological Modeling on Quranic "nature" domain. Proceedings of the IEEE 7th International Conference on Information and Communication Systems, pp. 151-155

[9] Tawil, S. F. M., Ismail, R., Wahid, F. A., Norwawi, N. M., \& Mazlan, A. A. (2016). Application of OASys approaches for dates ontology. Proceedings of the IEEE Third International Conference on Information Retrieval and Knowledge Management, pp. 131135.

[10] Al-Rumkhani, A., Al-Razgan, M., \& Al-Faris, A. (2016). TibbOnto: Knowledge representation of Prophet Medicine (Tibb AlNabawi). Procedia Computer Science, 82, 138-142.

[11] Ta'a, A., Abdullah, M. S., Ali, A. B. M., \& Ahmad, M. (2014, October). Themes-based classification for Al-Quran knowledge ontology. Proceedings of the IEEE International Conference on Information and Communication Technology Convergence, pp. 89-94.

[12] Alqahtani, M., \& Atwell, E. (2016). Arabic Quranic search tool based on ontology. Proceedings of the International Conference on Applications of Natural Language to Information Systems pp. 478 485 .

[13] Gómez-Pérez, A., Fernández-López, M., \& Corcho, O. (2006). Ontological Engineering: With examples from the areas of knowledge management, e-commerce and the semantic web. Springer Science and Business Media.

[14] Iqbal, R., Murad, M. A. A., Mustapha, A., \& Sharef, N. M. (2013). An analysis of ontology engineering methodologies: A literature review. Research Journal of Applied Sciences, Engineering and Technology, 6(16), 2993-3000.

[15] Yusof, N., Noah, S. A., \& Wahid, S. T. (2016). Ontology modeling of Malaysian food composition. Proceedings of the IEEE Third In- 
ternational Conference on Information Retrieval and Knowledge Management, pp. 149-154.

[16] Noy, N. F., \& McGuinness, D. L. (2001). Ontology development 101: A guide to creating your first ontology. Stanford Knowledge Systems Laboratory.

[17] Brusa, G., Laura Caliusco, M., \& Chiotti, O. (2008). Towards ontological engineering: A process for building a domain ontology from scratch in public administration. Expert Systems, 25(5), 484-503.

[18] Hakkoum, A., \& Raghay, S. (2015). Advanced search in the Qur'an using semantic modeling. Proceedings of the IEEE/ACS 12th International Conference of Computer Systems and Applications, pp. 14.

[19] Hakkoum, A., \& Raghay, S. (2015). Ontological approach for semantic modeling and querying the Qur'an. Proceedings of the International Conference on Islamic Applications in Computer Science and Technology, pp. 1-8.

[20] Pinto, H. S., \& Martins, J. P. (2004). Ontologies: How can they be built? Knowledge and Information Systems, 6(4), 441-464.

[21] Dombeu, J. V. F., \& Huisman, M. (2011). Combining ontology development methodologies and semantic web platforms for egovernment domain ontology development. International Journal of Web and Semantic Technology, 2(2), 12-25.

[22] Tsarkov, D., \& Horrocks, I. (2006, August). FaCT++ description logic reasoner: System description. Proceedings of the International Joint Conference on Automated Reasoning, pp. 292-297. 